\title{
Scientific results of the Mars Exploration Rovers, Spirit and Opportunity
}

\author{
W. Bruce Banerdt \\ Jet Propulsion Laboratory, California Institute of Technology, Pasadena, CA 91109-8099, USA \\ email: bruce.banerdt@jpl.nasa.gov
}

Abstract. Results of the Mars Exploration Rover mission to Mars are summarized.

Keywords. planets, space vehicles

\section{Results}

NASA's Mars Exploration Rover project launched two robotic geologists, Spirit and Opportunity, toward Mars in June and July of 2003, reaching Mars the following January. The science objectives for this mission are focused on delineating the geologic history for two locations on Mars, with an emphasis on the history of water. Although they were designed for a 90-day mission, both rovers have lasted more than two years on the surface and each has covered more than four miles while investigating Martian geology.

Spirit was targeted to Gusev Crater, a $300 \mathrm{~km}$ diameter impact basin that was suspected to be the site of an ancient lake. Initial investigations of the plains in the vicinity of the landing site found no evidence of such a lake, but were instead consistent with unaltered (by water) basaltic plains. But after a $3 \mathrm{~km}$ trek to an adjacent range of hills it found a quite different situation, with abundant chemical and morphological evidence for a complex geological history.

Opportunity has been exploring Meridiani Planum, which was known from orbital data to contain the mineral hematite, which generally forms in the presence of water. The rocks exposed in Meridiani are highly chemically altered, and appear to have been exposed to significant amounts of water. By descending into the $130 \mathrm{~m}$ diameter Endurance Crater, Opportunity was able to analyze a $10 \mathrm{~m}$ vertical section of this rock unit, which showed significant gradations in chemistry and morphology.

\section{Mission details}

Launch Dates: 10 June 2003 (Spirit), and 7 July 2003 (Opportunity)

Arrival at Mars: 4 January 2005 (Spirit), and 25 January 2005 (Opportunity)

Mass of each rover: $180 \mathrm{~kg}$

Primary science instruments:

PANCAM (Panoramic Camera): for determining the mineralogy, texture, and structure of the local terrain.

MINI-TES (Miniature Thermal Emission spectrometer): for identifying promising rocks and soils for closer examination and for determining the processes that formed Martian rocks. The instrument also looks skyward to provide temperature profiles of the Martian atmosphere.

MB (Mössbauer spectrometer): for close-up investigations of the mineralogy of ironbearing rocks and soils. 
APXS (ALPHA Particle X-ray spectrometer): for close-up analysis of the abundances of elements that make up rocks and soils.

Magnets: for collecting magnetic dust particles. The mössbauer spectrometer and the Alpha Particle X-ray spectrometer analyze the particles collected and help determine the ratio of magnetic particles to non-magnetic particles. They also analyze the composition of magnetic minerals in airborne dust and rocks that have been ground by the Rock Abrasion Tool.

MI (Microscopic Imager): for obtaining close-up, high-resolution images of rocks and soils. RAT (Rock Abrasion Tool): for removing dusty and weathered rock surfaces and exposing fresh material for examination by instruments onboard.

\section{In the literature}

The scientific results of the Mars Exploration Rovers have already been published in many hundreds of papers and abstracts, including special issues of Science, on 3 December 2004, and The Journal of Geophysical Research (Planets) in February 2006.

A recent overview of the Spirit Mars Exploration Rover mission to Gusev Crater, from the landing site to Backstay Rock in the Columbia Hills, can be found at Arvidson et al. (2006). A discussion of two years at Meridiani Planum, the results from the Opportunity Rover is summarized by Squyres et al. (2006).

\section{References}

Arvidson, R. E., Squyres, S. W., Anderson, R. C., Bell, J. F., Blaney, D., Brückner, J., Cabrol, N. A., Calvin, W. M., Carr, M. H., Christensen, P. R., Clark, B. C., Crumpler, L., Des Marais, D. J., de Souza, P. A., d'Uston, C., Economou, T., Farmer, J., Farrand, W. H., Folkner, W., Golombek, M., Gorevan, S., Grant, J. A., Greeley, R., Grotzinger, J., Guinness, E., Hahn, B. C., Haskin, L., Herkenhoff, K. E., Hurowitz, J. A., Hviid, S., Johnson, J. R., Klingelhöfer, G., Knoll, A. H., Landis, G., Leff, C., Lemmon, M., Li, R., Madsen, M. B., Malin, M. C., McLennan, S. M., McSween, H. Y., Ming, D. W., Moersch, J., Morris, R. V., Parker, T., Rice, J. W., Richter, L., Rieder, R., Rodionov, D. S., Schröder, C., Sims, M., Smith, M., Smith, P., Soderblom, L. A., Sullivan, R., Thompson, S. D., Tosca, N. J., Wang, A., Wnke, H., Ward, J., Wdowiak, T., Wolff, M., \& Yen, A.S. 2006, Journal Geophys. Res., 111, CiteID E02S01

Squyres, S. W., Knoll, A. H., Arvidson, R. E., Clark, B. C., Grotzinger, J. P., Jolliff, B. L., McLennan, S. M., Tosca, N., Bell, J. F., Calvin, W. M., Farrand, W. H., Glotch, T. D., Golombek, M. P., Herkenhoff, K. E., Johnson, J. R., Klingelhöfer, G., McSween, H. Y., \& Yen, A. S. 2005, Science, 313, 1403 